Canadian University Music Review

Canadian University Music Review

Revue de musique des universités canadiennes

\title{
Function and Structure of Transitions in Sonata - Form Music of Mozart
}

\section{Robert Batt}

Volume 9, numéro 1, 1988

URI : https://id.erudit.org/iderudit/1014927ar

DOI : https://doi.org/10.7202/1014927ar

Aller au sommaire du numéro

Éditeur(s)

Canadian University Music Society / Société de musique des universités canadiennes

ISSN

0710-0353 (imprimé)

2291-2436 (numérique)

Découvrir la revue

Citer cet article

Batt, R. (1988). Function and Structure of Transitions in Sonata - Form Music of Mozart. Canadian University Music Review / Revue de musique des universités canadiennes, 9(1), 157-201. https://doi.org/10.7202/1014927ar

All Rights Reserved (C Canadian University Music Society / Société de musique des universités canadiennes, 1988
Ce document est protégé par la loi sur le droit d'auteur. L'utilisation des services d’Érudit (y compris la reproduction) est assujettie à sa politique d'utilisation que vous pouvez consulter en ligne.

https://apropos.erudit.org/fr/usagers/politique-dutilisation/ 


\title{
FUNCTION AND STRUCTURE OF TRANSITIONS IN SONATA-FORM MUSIC OF MOZART
}

\author{
Robert Batt
}

The transition, sometimes referred to as the bridge, is usually regarded as the section of sonata form responsible for modulating from the primary to the secondary key as well as for effecting a structural contrast between the two thematic sections. Some sonata-form movements by Mozart have subsidiary and modulatory transition sections that contrast with neighboring thematic sections, such as the first movement of the Serenade in C Minor, K. 388. However, many movements do not have such well-defined transition sections. I will explain the great variety of transition functions and structures, accounting for the usual strategies that Mozart employs. These vary from movements without any apparent transition section, raising the question of the location of the transition functions (if, indeed, there are any transition functions in these movements), such as in the first movement of the Piano Sonata in C Major, K. 545, to movements that gradually ease into the new key area with a number of subsidiary sections, often combining thematic and transitional functions, such as in the first movement of the Symphony in D Major (Haffner), no. 35.1

1 In preparing this paper I studied primarily first movements of multimovement instrumental works written by Mozart between 1775 and 1791. I considered several examples within most of the major instrumental genres, including the symphonies, the sonatas for piano, the sonatas for violin and piano, the string quartets and quintets, and some other chamber music (e.g. the Flute Quartet in D Major, K. 285; the Serenade in C Minor, K. 388; and the Piano Quartet in G Minor, K. 478); concertos were not included. 
The subject of transition function and structure is usually treated in a general way in most textbooks on musical form or, in more detail, in studies of sonata form, of classical period music, or of Mozart's music. I will summarize here one author's views of transitions in order to indicate the typical sorts of statements made on this topic; the reader will find a summary of various other views of transitions in the appendix to the present paper.

Green (1979:195) categorizes the possible functions of the sonata-form transition as follows:

1. Modulation to the new key

2. Development of a motive or motives from the first theme

3. Introduction of a mood which contrasts with that of both first and second themes

4. Introduction of new material which contrasts thematically with both first and second theme

5. Preparation of the listener for the second theme by gradual change from one mood to another

6. Preparation of the listener for the second theme by anticipation of its characteristic rhythm or melodic motive

Like most textbook summaries of transitions (or other aspects of form), this one is not terribly useful because it is so general. Green admits that "no single transition can perform all these functions," and that "no one function is an indispensable feature of any transition" (p. 195). He also notes that transitions may not fully modulate to the new key or may not modulate at all, and that there may not even be a transition (pp. 195-197).

Symphonies will be identified by their numbers in the Breitkopf \& Härtel edition, and all other works by their original Köchel numbers. 
Green's discussion of modulation is more detailed, especially in his analyses of various transitions. He concludes that most transitions have three harmonic phases: the first, "that part before the modulation begins to set in," the second, "the deflection away from the tonic key by the introduction of the leading tone," and the third "is marked by the leading tone to V (i.e., \#4) of the new key" (p. 190).

Melodically, he classifies transitions as either "dependent," if they are based on first theme material, or "independent," if they are not. $\mathrm{He}$ uses Mozart's Piano Sonata K. 333 for discussion of these points, a discussion I will refer to below.

Briefly, some of Mozart's transitions do have some of the functions Green notes above, although there are other possible functions they may have, as I will discuss. Only a few of Mozart's transitions have all three of Green's "harmonic phases"; many have only the first two, some have only the second, and some have only the second and third.

In general, the remarks on transitions by Green and others (as noted in the appendix) are often useful, but there are other kinds of things to be said about transitions that will lead to a more complete picture of their functions and structures. With respect to Mozart's works, I will describe patterning at various levels with the aim of determining the unique features and structures of transitions, and how transition functions operate in the sonata form, even in the absence of a distinct transition section. A fundamental feature of eighteenth-century sonata form is that each section usually has a unique formal function and structure; what, then, are the function and structure of transitions in Mozart's works?

Transitions may be viewed from a variety of hierarchical levels and formal contexts. Essentially, one wants to know the internal structure of transitions and how transitions function in the exposition and the whole movement. The following outline of levels and contexts appropriate to this music includes brief definitions of the terms that will be used later. 
(1) Segments. Three types of segments are found on this level, each normally two bars long. Motivic segments are comprised of two 1-bar motives, a motive being characterized by a small number of linear (i.e., non-overlapping) pitches that form a unit by virtue of their close proximity in time and in register. The pitches usually form a highly differentiated rhythmic pattern, they are expressed in a single texture and in a single timbre, and they express one or two harmonies. A motivic segment is usually found in the predominating top voice of a complex of voices, set off from surrounding material by rests, long notes, or other linking material. See example 1, mm. 0(4)-2(3), varied in $\mathrm{mm}$. $2(4)-4(2) .^{2}$

Grouplets are either not repeated or are repeated only in a local context and in an obvious way, involving sequence and similar pattern formations. A motivic segment has long range significance and a pervasive melodic influence. A grouplet, on the other hand, is only a local event and need not even be repeated. A grouplet has fewer note values often only one or a prominent one among two or three - and few significant pitches. Grouplets often occur in immediate repetition without separation by rests. They often feature an equalized texture in which no single, clear melody emerges. See example 1, mm. 39-40, repeated in mm. 41-42.

A segment which has some features of motives and some of grouplets may be termed a motive/grouplet segment. This is how I would describe the segments in example 1, mm. 14(4)-17. (See the discussion of this piece below.)

Cadences are special types of grouplets - closing grouplets - that follow motivic segments. They are normally conventional formations, conventional in harmonic and melodic senses: for example, a perfect authentic cadence would often be two bars long, have the root-position

2 "M. 2(3)" means "measure 2, beat 3." Measure " 0 " is the bar before the first full bar. There is another type of motive several measures long - composed of long notes - which often leads to the first type of motive; e.g., the Symphony no. 41 , fourth movement, opening. 
harmonies V-I, with 2-1 in the melody. ${ }^{3}$ Coordination of harmony, melody, rhythm, and texture is necessary for there to be a cadence. One texture and one timbre must be maintained throughout the cadence. Expansions of cadence norms are possible, as are expansions of other segment norms. Such expansions usually occur in the context of an expansion at level 2: for example, a phrase might be expanded from four to eight bars, with its cadence segment being expanded from two to four bars. 4

(2) Phrases and groups. This next-higher level, normally of four bars length, is made up of motivic segments, grouplets, and cadences combining in various ways. Put simply, a phrase is a motivic segment followed by a cadence; see the four 4-bar phrases of the second theme, mm. 23-38, of example 1, the first three of which have weak, short cadences as the final bar of their second motivic segment, the fourth of which is more clearly "motivic segment plus cadence"; see also example 1, mm. 4(4)-10(3), which has two motivic segments followed by a cadence and is therefore six bars long.

A group is made up of two grouplets and is not punctuated by a cadence. See example 1, mm. 39-42. The majority of units at this 4-bar

3 See example 1, mm. 37-38, for a typical 2-bar cadence; here, as frequently happens, the dominant is preceded by dominant preparation harmonies, i.e., $\mathrm{ii}^{6}$ in $\mathrm{m}$. 37(1-2), and possibly also the I in $\mathrm{m}$. 36(3-4); and the sixteenthnotes in $\mathrm{m} .38$ form a link into the following section. (The cadence may therefore be considered to be from $\mathrm{m}$. 36[3] to 38[1].) The weak cadence in example 2, mm. 82-83, is such primarily in harmonic terms, as the $F$ : $I$ is the goal of the sequence begun in $\mathrm{m} .72 ; \mathrm{m} .83$ may be the end of a section but it is strongly overlapped with the start of a new section, thus weakening the cadence.

4 The distinction between motivic segments and grouplets may be clarified by reference to Rosen 1971:71-72, where he discusses "filling" and "conventional material," i.e., my grouplets, and at level-2, groups. See also the quotation from Kohs 1976 in the appendix to this paper: his "neutral material" is similar to my grouplet and group. Kohs' discussion of cadences is good, especially his table 4.2, "Factors affecting the weight of a cadence" (Kohs 1976:25-27). 
level fall between the two extremes of phrase and group: this will be illustrated in the subsequent discussion of transitions. ${ }^{5}$

(3) Small sections. The small sections vary from about eight to thirty bars in length and are of several types. Themes are normally eight bars long, are primary small sections, are composed mainly of phrases, are closed and non-modulating, and are based on two models, period and sentence. The period is composed of two 4-bar phrases with the motivic structure $\left(a a^{1}+(a b),(a b)+\left(a b^{1}\right.\right.$, or $(a b)+(a c)$. The first phrase usually ends with a half cadence, the second with a perfect authentic cadence, the harmonic-melodic structure often being that of the interruption (in the Schenkerian sense). ${ }^{6}$ This conception of the period is referred to elsewhere by names such as antecedent-consequent construction, symmetrical period (Green 1979:63), and parallel period (Kohs 1976:56). See the Piano Sonata in A Major, K. 331, mm. 1-8; see also example $1, \mathrm{~mm} .23-38$, a double period. ${ }^{7}$

The sentence has segment lengths of $(2+2)+(1+1+2)$ with motivic structure of $(a)+\left(a^{1} a^{1} b\right),\left(a a^{1}\right)+(b \quad b c),(a b)+(c$

5 The distinction between phrase and group may be supported by reference to Davis 1966:29 (quoted in my appendix, "areas of patterned harmonic rhythm that may occupy merely the dimensions of a phrase" is equivalent to my group); to Fairleigh 1986:26 (quoted in my appendix, "insignificant figuration"); to Kohs 1976:264 (quoted in my appendix, "neutral material"); to Kohs 1976:38 ("a dissolved phrase ... is a phrase which ends without a cadential close" is similar to my group); and to Green 1979:6-7 for general discussion of "phrase" and the difficulty of defining it, a difficulty that I believe is partially eased by restricting the definition to music of a specific style or composer. Although most level-2 units fall between the two extremes of phrase and group, understanding of all units on this level is facilitated by definitions of the two basic types that combine in various ways to form hybrids.

6 Schenker 1979:I, 36-40.

7 A double period has four 4-bar phrases. The fourth cadence is stronger than the second, which is in turn stronger than the first and third cadences. Normally, the first and third phrases are similar, as are the second and fourth. 
c d), or $(a b a b)+\left(a b^{1} a b^{1} c\right)$. Harmonic structure is often as simple as (I-V V-I) + (I PAC). The first four bars usually form a phrase with a weak cadence, resembling a compressed period in motivic structure. The second half of the sentence often develops a motive from the first half, and usually features fragmentation of material. Normally a strong cadence concludes the sentence. See example 4, mm. 14-21; and example $1, \mathrm{~mm} .1-10$, which contains a 2-bar expansion. ${ }^{8}$

Transitions will be discussed below.

Codettas and codetta-complexes are subsidiary small sections, and function in one of two ways, depending on their position in the sonata form; (1) they may occur singly, as codettas to themes, and (2) they may combine with other codettas to form larger, more independent small sections called codetta-complexes, possibly in place of or following a theme and as part or all of a closing section or coda. Harmonic motion in a codetta is usually limited to simple progressions, and often involves tonicization of the subdominant, perhaps over a tonic pedal. 9 Codettas are usually composed of groups, not phrases. Closing sections are usually made up of a codetta-complex, but may include material based on the thematic models. In example 1, mm. 39-63 form a particularly complicated illustration of a codetta-complex. ${ }^{10}$

8 This conception of the sentence differs from that in most English-language texts, most of which do not use the term. For one that does, see Schoenberg 1967:20-81, in which he discusses both the period and the sentence in the meanings in which I use the terms; he includes many examples, some from works of Mozart. See also Ratz 1973:21-25, and Caplin 1987:218-219, 222-223, for similar uses of these terms.

9 Transitions may therefore be distinguished from codettas to main themes by virtue of the fact that transitions will tonicize $\mathrm{V}$, whereas codettas will tonicize IV.

10 This codetta-complex is more involved than most partially because it has additional formal functions. Measures 56-59 form an "expanded cadential progression" (for discussion of this latter term, see Caplin 1987). Measures 59-63 form a truncated closing section (see Batt 1988 for further discussion 
Introductions and codas are optional subsidiary small sections.

(4) Large sections. Most expositions and recapitulations can be successfully analysed in terms of the standard four-small-section model: main theme - transition - subordinate theme - closing section (MT-TR-ST-CS), where the main theme and the subordinate theme are primary small sections and the transition and closing section are subsidiary small sections. The functional differentiation of units is greater on this level than on any other level: each of the four small sections is distinguished by unique features. (This characteristic is somewhat analogous to the differentiation of rooms of a house brought about by features unique to each room.) Even in an exposition having more or fewer than these four small sections, the function of each is usually present in some altered form; for example, a double-function small section might replace two separate small sections.

Development sections may be composed of two or three small sections or may be short and continuous enough to be seen as one small section having more than one function. (Discussion of development techniques is unnecessary here.)

(5) Movement. The entire movement is always composed of the three large sections - exposition, development, and recapitulation - and the outer two of these often have the same form, with the exception of the necessary transposition of the second-key material to the tonic. ${ }^{11}$ (Changes to the recapitulation often occur in the transition, as will be noted below.) If the mode of the movement is major, the second key will be the dominant; if the mode of the movement is minor, the second key will be the relative major. About ninety percent of Mozart's instrumental works are in the major mode. Most works have the repetition pattern

||:Exposition:||:Development-Recapitulation:||.

of closing sections and, generally, of the analytical approach outlined in this paper).

11 Although I believe most of Mozart's sonata-form movements may be seen as tripartite at level 5, some may perhaps be analysed as bipartite. For discussion of bipartite and tripartite approaches, see Newman 1983:143-147. 
The ratio of lengths of the three large sections is on average about 2:1:2. Absolute lengths in common-time allegro for the sections average about 80,40 , and 85 bars respectively, without repetitions taken into account.

The fifth level - the entire movement - is of least interest for the study of transitions. The remaining four levels are useful as a vehicle enabling one to see the structure and function of transitions in terms of (i) the types of level-1 and -2 units characteristic of transitions, and (ii) the level-4 context in which transitions function. Specifically, level 3 is interesting for two reasons: it is here that the lower-level units that constitute transitions will be seen, and it is on this level that the differences between the transition and the other small sections are most apparent. Level 3 is in fact the most interesting single level because it has the greatest variety of units and because, as in other hierarchical theories, such as Schenker's, the middleground level reveals the most about the music.

Figure 1 shows one common model of how units on level 1, 2, and 3 vary within the exposition. This pattern also applies in large part to the recapitulation. It should be emphasized that this is only one model, and an incomplete one, for exposition structure. The two themes, which appear to be equivalent in the diagram, are distinguished by certain other features, such as tonality. This factor, among others, also differentiates the two subsidiary small sections.

Level Exposition

(3)

(2) \begin{tabular}{l|l|l|l} 
main theme------ & -- transition---- & second theme--- & closing section \\
phrases--------- & phrases-->groups & phrases--------- & phrases \& groups \\
motivic segments & $--->$ grouplets-- & motivic segments & $---->$ grouplets
\end{tabular}

Note: Arrow means "becoming."

Figure 1. : A model of exposition structure 
Transitions differ from thematic small sections in that transitions are subsidiary as opposed to primary small sections, and also in that there are no models that account for their melodic, rhythmic, and harmonic features. Transitions have a subsidiary function because their features are looser in construction than are those of themes. (This is particularly apparent in that transitions follow main themes, which have very closed constructions.) The fact that transitions cannot be explained by models means that it is more difficult to present a detailed and overall view of transitions.

The looser construction of transitions is generated by the following normative features:

1. In those cases where a thematic model - period or sentence - is used for all or part of a transition, the model will invariably be radically altered in its projection into a transition. Regardless of whether any thematic model is used, the segment structure will be looser because (i) both motivic segments and grouplets will be used, together with both phrases and groups (there will often be a shift from one to the other, usually motivic segments and phrases becoming, respectively, grouplets and groups), and (ii) motivic associations within the transition will be weaker, to the point where each phrase/group may have different motives/grouplets, and there may be motivic associations with both the preceding main theme and the succeeding subordinate theme. In short, the transition usually has a series of motives/grouplets based on unrelated materials.

2. Transitions often include a modulatory function, although it is often attenuated in the recapitulation form of the transition. (The fact that there are often two quite different forms of the transition - an exposition form and a recapitulation form - is another reason why there are no models for transitions.) Whatever the nature or extent of the modulation, such modulation means that the transition will be open-ended, as opposed to closed, as is the norm for thematic small sections (the latter not usually having 
modulations). 12 All transitions are open-ended, no matter how weak or strong the modulation. This open-ended feature is usually preserved in recapitulation forms of transitions: where the transition ends on $\mathrm{V} / \mathrm{V}$ in the exposition, it will usually end on $\mathrm{V}$ in the recapitulation; where it ends on $\mathrm{V}$ in the exposition (i.e., where there is no strong modulation), it will usually be rewritten in the recapitulation so that it still ends on $V$. Rarely will such a transition not be altered in the recapitulation, even though there is no apparent need for such alteration. ${ }^{13}$

3. The timespan (or hypermeasure) structure is not uniformly periodic ("periodic" here meaning successions of equal-length units). Whereas the thematic models employ timespans that are periodic at both the 2- and 4-bar levels, transitions are not entirely governed by such patterning on any timespan level. Normally, a regularity is established, often at the 2-bar level, at the beginning of the transition (for example, based on the main theme opening). This regularity is then upset at some point, and is followed by a series of unequal timespans, in addition to possibly some short successions of similar timespans. ${ }^{14}$

12 For an illustration, see example 1, in which the first theme ends with a perfect authentic cadence in the tonic, in mm. 9-10, and the transition ends on $\mathrm{V} / \mathrm{V}$ (after modulating from I), in $\mathrm{m}$. 22; i.e., harmonically, the theme is closed, the transition open.

13 For an illustration of the type of change involving a transition ending on V/V, see the Piano Sonata in B-flat Major, K. 333, where the transition is altered in the recapitulation to end on V (mm. 104-118). For an illustration of a typical minor mode example, see the Piano Sonata in A Minor, K. 310, where in the exposition the transition moves from i to V/III (mm. 9-22), and in the recapitulation from $i$ to $V(\mathrm{~mm} .88-103)$. For an illustration of a major mode transition ending on $\mathrm{V}$ in the exposition, see the Symphony in B-flat Major, no. 33, mm. 25-54 and 232-263: both versions of the transition end on V, but the recapitulation version takes a circuitous harmonic route in arriving there.

14 The timespan structure, together with the segment structure discussed in 
In summary, the melodic structure, the harmonic structure, and the timespan structure of transitions are all intrinsically irregular, at least in that they all contrast with the more regular structure of the first theme. This complex of irregular structures is responsible for the loose, open nature of transitions.

Although it is not realistically possible to formulate models that take into account all features of transitions, it is possible to categorize the general functions of transitions. The modulatory function of transitions is the central one, with melodic and textural contrast to the surrounding small sections being the lesser functions. Four broad categories of transition procedures can be identified:

1. A very few works have no transition small section. In such works transition functions may be transferred to the main theme, which may, for example, end on or in the dominant; the thematic function will be primary in such cases. For example, see the Piano Sonata in C Major, K. 545, where the first theme ends on the dominant in mm. 11-12, and where m. 13 substitutes for an independent transition section. (Note how m. 13 acts rhythmically to disrupt the otherwise smooth flow of 4-bar timespans, thereby fulfilling the transition function of metric irregularity.) See also the Piano Sonata in D Major, K. 311, where the main theme, in mm. 1-16(3), ends with dominant prolongation, the subordinate theme following.

2. The majority of movements have a distinct transition small section, varying from about eight to twenty-five bars in length. Examples of this type are numerous: see the Piano Sonata in B-flat Major, K. 333, the exposition of which is shown in example 1 in this paper; see also example 4 in its second interpretation as discussed below; and see also example 3 .

paragraph (1), are discussed in connection with various transitions later in the paper. See, for example, the discussion of example 1 in the text. 
3. A few movements have a series of small sections in which the modulatory function is divided so as gradually to shift the tonal focus from the tonic to the new key. For example, the first of two small sections might end on the dominant, with the second ending on the dominant of the dominant; see the String Quartet in D Major, K. 593, where the first small section, in mm. 33(4)-45(1), is based closely on the main theme, rewritten to end on $\mathrm{V}$, and the second, in mm. 45-63, develops a main theme motive, ending on V/V. See also the Symphony in E-flat Major, no. 39, which is discussed below.

4. A few movements combine transition and subordinate theme functions in one or more small sections. For example, see the Symphony in D Major (Haffner), no. 35, and the Sonata for Violin and Piano in F Major, K. 377, both of which are discussed below.

A brief discussion of features commonly found in transition sections is appropriate here, followed by analyses of some examples illustrating the four types noted above. The main variable affecting the tonal plan of the exposition and recapitulation is the mode of the movement. In the major mode the transition will move toward the key of the dominant, and in the minor mode the transition will move toward the key of the relative major. The way the second key is approached harmonically is quite variable: often the transition begins in and with the tonic, but there are cases in which the transition begins with the relative minor or the parallel minor key. ${ }^{15}$ The progression toward the new key is usually clear and direct, although the middle area of the transition is sometimes

15 Tonic beginnings are the most common; see, for example, the transitions in examples 1 (m. 10[4]), 2 (m. 54), and 3 (m. 22); all are of this type. (The transitions in examples 1 and 3 begin as variants of the main theme and rapidly move away from the tonic. The transition in example 2 begins with a contrasting section. All three will be discussed later in the paper.) The transition in the Piano Sonata in F Major, K. 332, begins in m. 22(3) in the relative minor. The transition in the String Quartet in D Minor, K. 421, begins abruptly in the relative major in $\mathrm{m}$. 14. The transition in the String Quartet in A Major, K. 464, begins in the parallel minor in m. 17. 
tonally unstable, especially if the transition begins on the tonic. 16 The final harmonic area of the transition is a simple prolongation of either the dominant of the secondary key, or less often, the tonic of the secondary key, a prolongation often as simple as a pedal. ${ }^{17}$

There is no general correlation between melodic and harmonic processes in transitions. That is, a transition that begins as a variant of the main theme would not necessarily begin in the tonic key. ${ }^{18}$ Similarly, a tonic beginning would not necessarily be associated with a main theme variant. 19 There are also examples of non-tonic beginnings that are not main theme variants. ${ }^{20}$ Although the transition that begins as a main

16 The modulation in example 1 is simple and yet very effective, moving directly and smoothly to the dominant; the modulations in examples 2 and 3 are longer and slightly more involved. The transition in the Serenade in E-flat Major, K. 375, is tonally unusual in that it involves a subsection in the dominant minor in mm. 38-47 (a subsection so independent and thematic in nature that it could be termed a transition theme). For an example of a transition involving a particularly complex harmonic progression, see the String Quartet in E-flat Major, K. 428, mm. 12-40.

17 For illustrations, see example 1, mm. 18-22; example 2, mm. 83-96 (this one is somewhat complicated by the descending-fifth line in $\mathrm{mm}$. 89-96, to be discussed later in the text); and example 3, mm. 34-39.

18 An illustration of a transition that begins as a main theme variant in the tonic key is in example 1, m. 10(4)ff. The transition in the String Quartet in A Major, K. 464, begins in $\mathrm{m} .17$ as a main theme variant in the tonic minor. The transition in the Symphony in D Major(Prague), no. 38, begins in $\mathrm{m} .72$ in the dominant key as a main theme variant (although it would be possible to see the transition beginning earlier in the movement, perhaps at $\mathrm{m} .51$ or $\mathrm{m} . \mathbf{5 5}$ ).

19 Although the transition that begins as a main theme variant in the tonic key is a common type, there are examples of transitions beginning in the tonic with new material; see, for example, the Symphony in D Major (Paris), no. 31, mm. 32-51.

20 Transitions beginning with contrasting material and not in the tonic are fairly common; see for example the Piano Sonata in F Major, K. 332, mm. 22(3)-40. 
theme variant is a common type, many sorts of continuations are possible. At one extreme, the transition has the same timespan and motivic form as the main theme, and begins in the tonic but ends with a modulation. ${ }^{21}$ At the other extreme, the transition has only a brief reference to the main theme at its beginning, possibly in combination with new material. ${ }^{22}$ Other types of transitions are composed of entirely new material. ${ }^{23}$ In general, transitions introduce new motivic material in addition to a new tonality, with or without previous motivic material and reference to the tonic key. Some authors, especially of textbooks, consider melodic preparation for the second theme to be a function of transitions, in the sense that a transition will often introduce some of the motives or other features of the upcoming theme (see, for example, Green 1979, discussed above, and Kohs 1976, discussed in the appendix). I have not found this to be the case with many of Mozart's transitions (an exception is in the String Quintet K. 516). My conclusion is supported by Fairleigh (1986:18).

An interesting feature of some transitions is that they are marked by a textural and dynamic change from the preceding main theme. The transition will feature an increase in dynamic level, a thicker texture (achieved, for example, in a symphony by the addition of the winds), and an increase in surface rhythmic activity. The effect of these features is to heighten the contrast with the preceding main theme and also to give the movement a renewed sense of momentum after the closure of the main theme. A clear example of this is found in the Symphony in E-flat Major, no. 39 (see example 2). The transition begins at $\mathrm{m}$. 54 , contrasting with the main theme in dynamics, texture, and motives. The first small section (in $\mathrm{mm}$. 54-71) does not move away from the tonic key and might be considered a main theme codetta-complex -

21 See example 4, the second interpretation of which involves seeing mm. 22-29 as a transition. (This is discussed later in the text.)

22 See example 3, where the transition begins in $\mathrm{m} .22$ using the main theme motive in the bass with new material added above.

23 For example, see the Piano Sonata in F Major, K. 332, mm. 22(3)-40, composed entirely of new material with no reference to the tonic key. 
on harmonic grounds - except that dynamics, texture, and motives associate it more with the succeeding small section rather than with the preceding one. This phenomenon of the transition initiating a new kind of momentum is found to a greater or lesser extent in most movements.

Symphony no. 39. Of the four types of transitions noted above, the one in the Symphony in E-flat Major, no. 39, is an example of type (3), in which the transition functions are split into two or more small sections. The first of these sections here is in $\mathrm{mm}$. 54-71, as noted in the preceding paragraph (see example 2). This section initiates melodic and textural contrast with the main theme and is characterized by motivic segments and phrases; the second section, in mm. 71-83, primarily functions as a modulation by tonicizing the dominant of the dominant, and has primarily grouplets and groups. However, the first section also hints at the dominant by introducing several A-naturals. And the second section also has the melodic function of motivic association: the sixteenth-note scale motive is similar to that in the introduction.

After reaching the tonicized dominant of the dominant in $\mathrm{m} .83$, and after prolonging this harmony with a pedal for several bars (mm. 83-87), the transition might have ended. However, in this transition Mozart adds a third section which introduces a new 2-bar motive (in mm. 89-90, etc., in sequence), and prolongs the $\mathrm{V} / \mathrm{V}$ with a descending fifth-line in octaves (F - E-flat - D - C - B-flat).

The arrival of the tonic of the new key in m. 97 is, unusually, not quite coincident with the start of the second theme, which really begins in m. 98. This lack of simultaneity is confirmed by the 2-bar motives and timespans which start in m. 98, (i.e., mm. 98-99, 100-101, etc.); in particular, mm. 102-103 repeat mm. 98-99, and m. 97 is never re-used. Measure 97 is successful as a link between the transition and the second theme because (1) it gives a brief but necessary break from the otherwise constant flow of faster-moving note values characteristic of this - and of most - transitions; (2) it functions as a link between two different motives; and (3) it arrests the continuity of 2-bar timespans because it is a 1-bar unit. At first it appears to be connected with m. 98, but, as 
noted above, m. 98 subsequently is heard as joined to $\mathrm{m} .99$. The use of 2-bar timespans prior to m. 97 goes back as far as mm. 71-72, and possibly as far back as mm. 61-62. This transition is somewhat unusual in its almost constant use of 2-bar timespans; this is perhaps as a contrast to the main theme, which is somewhat irregular in its use of metric units, and to the second theme, which, although beginning with 2-bar timespans, also uses some irregular ones (m. 110ff.). From this point of view, this transition reverses the normal type of contrast between the two themes and the transition, in which the themes have periodic timespans and the transition has irregular ones. In summary, then, the three functions of m. 97 noted above serve to distinguish the second theme. Measure 97 provides a bar of rest between the transition and the second theme without actually being a bar of silence.

The recapitulation of this movement is similar to the exposition with the main exception of the closing section, which is expanded from its very brief length in the exposition. The transition is very similar to its exposition form except for a change in $\mathrm{mm}$. 223-227 (relative to $\mathrm{mm}$. 65-70) that directs the cadence to IV instead of to I. The subsequent modulation is therefore IV-I instead of I-V.

Piano Sonata K. 333. An illustration of a type (2) transition that begins as both a main theme variant and in the tonic key is found in example 1, the Piano Sonata in B-flat Major, K. 333, mm. 10(4)-22. The modulation is accomplished quite quickly, with the transition ending with a prolonged tonicized dominant-of-the-dominant harmony in $\mathrm{mm}$. 18-22. The characteristic shift from motivic segments to grouplets is clearer and more interesting in this transition than in the one in example 2 , and so will be discussed in detail here.

In example 1, all of the non-cadential segments in the main theme, in mm. 1-10, are motivic. Here the segments are separated by relatively long note values - that is, the dotted quarter-notes in the first three bars, or by subsidiary link material (in mm. 6 and 8), rather than by rests between motives, only one of which is found here, in m. 4. A gradual shift to grouplets begins in mm. 10(4)-14(2), the beginning of the transition. The sixteenth-note linking material, a string of equal 
note-values, is used in this variation of the opening four bars to weaken the motivic nature of mm. 12(3)-14, while at the same time there is no doubt that these bars are a variation of a previously-heard motive.

The statement of a motive three times in mm. 14(4)-17 is a different kind of weakening of motivic character. Here, although these three segments are intrinsically motivic, their overall motivic character is weakened because they are almost identical, immediately adjacent without being separated by rests or long notes, and used with a similar, simple cadential progression $\left(\mathrm{F}: \mathrm{V}^{4 / 2}-\mathrm{I}^{6}\right)$. This is a relatively local indication of the fact that one must often go beyond the segment level to determine motivic character. Each individual segment is motivic, but the way these three segments are used in the larger unit is not.

Repetition in themes is different from that in transitions and closing sections; that this is possible should be obvious, because repetition in general is a feature of most musical styles. Repetition of level-1 units in mm. 14-17 differs from that in, for example, the main theme of this movement in the following ways: (i) there is no separation between the segments in mm. 14-17; (ii) continuity is further established by the continuous eighth-note bass voice, a voice which is also even less motivic than in the theme; and (iii) the distinction between the level-1 units of motivic segments and the next lower level of motives is lost: the unit in mm. 14(4)-15(3[1]) is a compression to one bar of the 2-bar motivic segment in $\mathrm{mm}$. 4(3)-6(2), and $\mathrm{mm}$. 14(4)-17 are therefore comprised of three similar 1-bar compressed segments followed by a half-bar extension to the end of m. 17. So whereas mm. 10(4)-14(3) form a phrase comprised of two motivic segments, mm. 14(4)-17 form a group comprised of three motive/grouplets. One reason for this latter level-2 unit forming a group rather than a phrase is that it is not cadenced. It might be considered to end on the downbeat of $\mathrm{m}$. 18, thus forming a half cadence in $F$ major, except that the cadence is overlapped with the new material in $\mathrm{m} .18$.

The weakening of the motivic character of this transition is further accomplished by the two grouplets in mm. 18-22. Each of the previous motivic segments and motive/grouplet segments began with an anacrusis and had a beginning and ending that were clear, except for 
the ending of the motive/grouplet segment in mm. 16(3)-18(1). The two grouplets in $\mathrm{mm}$. 18-22 have no anacrusis and have beginnings and endings that are partly created externally rather than internally by cadences. That is, each of these two grouplets begins on a downbeat and ends on a downbeat three bars later (except for the extension here of the second grouplet through $\mathrm{m}$. 22), overlapping with the start of the second grouplet in m. 20. Although these units are more grouplet-like than those in mm. 14-17, they are not as completely so as the model grouplets in mm. 39-40 and 41-42 (the latter are completely selfcontained, in that they end on I, whereas the former can end only with the downbeat harmony, and thus involve overlapping, a feature not present in mm. 39-42). Also characteristic of these grouplets is the use of only two note values (and these not in combination but in separate bars), and the use of common figuration patterns, that is, the passagework in mm. 18 and 20, which is found in many pieces. The use of low-level sequencing of the figure in $\mathrm{mm} .18$ and 20 , forming a series of 1-beat long sub-grouplets, and the use of parallel tenths throughout are also common features. (Outer-voice parallelism is a feature of grouplets because it is the opposite of the standard motive/accompaniment texture found in motivic segments; parallelism is thus a way of generating the equalized texture charactersitic of grouplets and groups.) Overall, then, there has been a gradual change from motivic segments to grouplets over these bars, mm. 11-22.

Serenade K. 388. An illustration of a type (2) transition in the minor mode is found in the Serenade in C Minor, K. 388, part of which is shown in example 3. The transition begins at $\mathrm{m}$. 22, overlapping with the end of the main theme, and beginning with a variant of the opening 5-bar phrase of this theme. The transition varies the phrase by adding a new eighth-note motive to the 5-bar phrase, as well as by adding a 1-bar extension - m. 27 - that begins the modulation to the relative major. A sequence of three 2-bar grouplets, in $\mathrm{mm}$. 28-33, leads to a tonicization of the dominant of the relative major (or, as it appears, to the dominant of the parallel minor of the relative major - and this effect is quite common, no matter what the mode of the movement; in movements in the major mode, the dominant of the parallel minor of 
the dominant key would be tonicized). ${ }^{24} \mathrm{~A}$ further succession of three 2-bar grouplets comprises the usual prolongation of the dominant of the secondary key. The more periodic nature of this transition $-(5+1)$ $+(2 \times 3)+(2 \times 3)$, or $(6+6+6)-$ is perhaps due to the need for some periodicity to balance the highly irregular nature of this movement's main theme, which is not based on any of the thematic models.

The process of regularization of lengths of groups, phrases, and timespans is begun in the transition with the 1-bar extension to the variant of the opening phrase (mm. 1-5; 22-27), as noted above. The two succeeding 6-bar phrases (mm. 28-39) are followed by a 2-bar link to the subordinate theme, which also features prominent use of 6-bar phrases. The closing section, in mm. 66-94 (which also functions as a codetta-complex to the second theme), normalizes lengths even more in its use of 8-bar groups. Here is the timespan summary for the exposition:

MT: $(5+4)+3+(2+2)+(1+1+2)+1$ (mm. 1-21)

TR: $(6 \times 3)+2$

(mm. 22-41)

ST: $\left(\begin{array}{lll}6 & \mathrm{X} & 4\end{array}\right)$

(mm. 42-65)

$\mathrm{CS}:(8 \times 2)+(4 \times 2)+5$

(mm. 66-94)

This exposition may therefore be seen as having a process of periodization: the main theme sets up a dissonance of timespans that resolves in succeeding small sections.

This process of periodization is important to the recapitulation of this Serenade as well, despite the fact that considerable re-writing takes place. The main theme is the same as in the exposition. The transition begins as in the exposition but becomes greatly changed; its timespan and grouplet structure is $(2 \times 4)+(2 \times 3)+(2 \times 2)+(2 \times 4)$, that is, a series of 2-bar units grouped in different ways. The recapitulated

24 For an illustration in the major mode, see K. 375, referred to in note 16. 
second theme is very interesting: it is motivically different from the second theme in the exposition, yet it maintains exactly the same timespan structure, that is, $(6 \times 4)$. The closing section is lengthened slightly, but is otherwise the same as in the exposition.

Violin Sonata K. 454. Occasionally, a small section can be interpreted in more than one way. In the Sonata for Violin and Piano in B-flat Major, K. 454, two parts of which are shown in example 4, the exposition-main theme may be heard as a period of sixteen bars length, that is, in mm. 14-29(2). The two 8-bar phrases are motivically very similar, with the cadence of the second phrase stronger than that of the first. Because the first theme ends on the dominant, the second theme can enter immediately, as it does in m. 29(3), ending in $\mathrm{m}$. 50. (This procedure is seen especially in shorter and earlier works; see, for example, the Piano Sonata in C Major, K. 545, which has no transition section.) A difficulty with this interpretation, beyond the obvious lack of a transition section, is that it is unusual in Mozart's style to have a modulating theme: this theme does not merely end on the dominant (as the K. 545 theme does), it modulates to the dominant with a perfect authentic cadence in V. In this interpretation, then, the transition function is absorbed into the end of the main theme, making this a type I transition.

An alternative analysis of $\mathrm{mm} .14-29$ is that the main theme is eight bars long, in mm. 14-21, and that it is followed by an 8-bar transition, in mm. 22-29. This view is supported by the following points: (1) The 8-bar theme is a model sentence. (2) The transition is normal, except that it is more periodic than ususal. (3) It is far more common in this style to have a main theme followed by a transition than to have a modulating main theme without a subsequent transition. ${ }^{25}$ (4) The main theme in the recapitulation repeats only the first eight bars (i.e.,

25 This is a good illustration of the problem of using models for analysis: should the main theme-transition norm dictate our interpretation of this movement? I believe knowledge of the norm should be only one factor in the analysis. And some of these movements, such as this one, do contain 
mm. 90-97 recapitulate $\mathrm{mm}$. 14-21). It is in the recapitulation that we finally get a normal transition, in mm. 98-114 (see example 4). This transition is a new small section, replacing $\mathrm{mm}$. 22-29 with a sequential development of the opening main theme motive that leads to the usual dominant pedal in mm. 111-114.

This second interpretation involves seeing both exposition and recapitulation forms as type (2) transitions. In the first interpretation it would be possible to see mm. 90-114 as one section; although, because mm. 98-114 are not parallel to $\mathrm{mm}$. 90-97 as $\mathrm{mm}$. 22-29 were parallel to $\mathrm{mm}$. 14-21, it would be preferable to see mm. $90-114$ as two sections, a main theme followed by the transition missing from the exposition.

Another way to evaluate these two interpretations of this movement is on the basis of relative lengths of the small sections. An examination of Mozart's works will reveal that most expositions have approximately equal-length small sections and that it is unusual for a small section to be very much longer or shorter than the other ones in a given exposition. The second interpretation of the exposition of K. 454 involves four small sections having lengths of $8,8,20$, and 16 bars, or a ratio of $2: 2: 5: 4$. The first interpretation involves three small sections with a more balanced ratio of 4:5:4. The near-equality of small sections in this latter view is evidence for considering $\mathrm{mm}$. 14-29 as one small section rather than as two. The introduction, in mm. 1-13, if considered part of the exposition, may have some of the functions of the missing fourth small section: first, it is a fourth section (or, rather, the first of four), and second, it does have the modulation from tonic to dominant that would be found in the transition. In this work the introduction does help to explain why there are only three small sections in one of the interpretations.

Symphony no. 35. An illustration of a type 4 transition, in which the transition and second theme functions combine in one or more small sections, is found in the first movement of the Symphony in D Major

small sections that may be analysed in more than one reasonable way, in the sense that a small section could be assigned more than one formal function. 
(Haffner), no. 35. The exposition model, noted above, does not apply very well to this work for the following reasons: (1) This exposition is unusually continuous, due to a great deal of overlapping of small sections and to the lack of divisions in the texture. (2) There are many more than four small sections, the functions of which are not always clear, at least not in the sense of primary, or thematic, versus subsidiary small sections. That is, the primary/subsidiary distinction is blurred, partly because the thematic models are not used, or are used as extreme variants. (3) The modulation is accomplished in an unconventional way. A move to the dominant begins in $\mathrm{m} .24$ but is arrested in $\mathrm{m} .41$ with a prominent return of the tonic and the main motive. A stronger move to the dominant follows. (4) A single motive dominates the melody, and there is no strong candidate for second theme. From $\mathrm{m}$. 13 to m. 94, the end of the exposition, there are several small sections that have thematic, transitional, and closural functions. ${ }^{26}$

The works cited so far have illustrated the four types of transition procedures as well as the ways that the transition functions - essentially, modulation and contrast - are found in these works. If space permitted, several more movements could be discussed in order to illustrate the many variations of these types. ${ }^{27}$

26 Another example of a type 4 transition is in the first movement of the Sonata for Violin and Piano in F Major, K. 377. Unlike the Haffner Symphony, however, there are clearly-defined small sections, in this case three: a main theme in $\mathrm{mm}$. 1-17, a section combining transition and second theme functions in $\mathrm{mm}$. 18-36, and a closing section in $\mathrm{mm}$. 37-51.

27 For example, some type (2) transitions proceed to a pedal on the tonicized dominant, giving the impression that the subordinate theme will follow immediately, this being one of the standard harmonic plans of type (2) transitions. Instead, however, the transition continues with an extension to a pedal on the tonicized dominant of the dominant. A simple and short example of this is found in the first movement of the Serenade/Eine kleine Machtmusik) K. 525, in mm. 18-27. This procedure allows for the second part of the transition - the part that tonicizes the V/V - to be simply omitted in the recapitulation in order to have the transition there end on the dominant: this is exactly what happens in K. 525 , in $\mathrm{mm}$. 93-100. So, the 
Several examples of alterations to transitions in the recapitulation as compared with their exposition forms have been mentioned. I will conclude this paper with an outline of the types of changes the transition undergoes in recapitulation sections. In general, about seventy-five percent of movements have similar exposition and recapitulation structures at level 3 and 4 (i.e., the overall form of their expositions and recapitulations is the same) except for the required transposition of secondary-key material to the tonic. However, the percentage of movements having differences between their expositions and recapitulations rises somewhat when viewed from levels 1 and 2: for example, slight variations of a motive or phrase are not uncommon. A list of the types of recapitulation variation follows, with some examples of each type, starting with alterations at lower levels.

(1) Some works have no alterations at all in the transition section. This occurs usually when the transition ends on the dominant in both exposition and recapitulation, as in the Piano Sonata in D Major, K. 284. Two works having almost no alterations are the String Quartet K. 458 and 499. Both have slight alterations permitting the transition to remain in the tonic, and both have substantial codas.

(2) Differences in orchestrating the same material are sometimes found. This involves either giving the material to a different instrument, possibly in a new register, or altering the doubling of or accompaniment to a melody. Assigning material to different instruments is a feature of quartet style, especially in the three String Quartets (Prussian), K. 575,589 , and 590.

(3) The addition of embellishments and other surface ornamentation to transitions is not common, probably because transitions are usually quite active on the surface to begin with.

impression, given in the exposition, that the transition would end on the dominant, is confirmed and realized in the recapitulation. A longer and more involved example of this type of transition is found in the first movement of the Symphony in C Major (Jupiter), no. 41, in mm. 24-55; the recapitulation, however, unlike that of $\mathrm{K}$. 525, includes both pedals, the second one transposed to the dominant, in $\mathrm{mm}$. 212-243. 
(4) The few minor mode works usually have a greater variation to the recapitulation than do major mode works. (A prominent exception to this is the Symphony in G Minor, no. 40, where the exposition and recapitulation are very similar.) Examples are the String Quartet in D Minor, K. 421, where the transition and second key areas are greatly rewritten; and the Piano Sonata in C Minor, K. 457, where a new melody replaces one in the exposition, in mm. 19-35, 118-130.

(5) Harmonic alterations are sometimes seen in the opening of a transition, where they are not strictly required. See the Symphony in C Major (Jupiter), no. 41, where, although the transition ends with the same material as in the exposition, the first part, from m. 212, is harmonically very different.

(6) Alterations in the length of the transition are common: these are usually prompted by the need to re-direct the harmony, although sometimes other factors come into play. An interesting one that is perhaps not as trivial as it first appears - because it alters the metric position of the entire subsequent small section - is in the transition of the String Quartet K. 421. As noted in paragraph (4) above, this transition is greatly rewritten: part of the alteration involves a half-bar expansion from ten-and-a-half to eleven bars. This shifts the following theme so that its melody begins on the third beat (of m. 94) instead of on the downbeat (of m. 25). Another interesting movement that includes level-3 recapitulation expansions is in the Symphony no. 40: the transition, subordinate theme, and closing section all feature expansions with respect to their exposition forms.

(7) A special case of expansion or contraction as development may occur towards the end of the main theme, and may include part or all of the transition. Rosen refers to this as the "secondary development" (Rosen 1980:276-277). An illustration has been seen in the Sonata for Violin and Piano K. 454, example 4, where the second half of the 16-bar main theme is replaced in the recapitulation by a sequential development, in $\mathrm{mm}$. 98-111, and by a dominant pedal, in $\mathrm{mm}$. 111-114. In the Symphony no. 34, the 20-bar main theme and 20-bar transition are replaced in the recapitulation by a single 19-bar small section, in $\mathrm{mm}$. 158-176, that at first resembles the main theme, then 
incorporates some sequential development, and ends with a dominant pedal, a transposition of the end of the transition (which had ended with a pedal on the dominant of the dominant). Some of the missing material is recapitulated later in the recapitulation. Similar contractions of the main theme and transition into one small section are seen in the Symphony no. 38 and the String Quartet K. 465. This procedure is obviously a radical one, in that it gives the recapitulation a different form at levels 3 and 4 ; there are often other factors that should be taken into account, however, such as the subsequent recapitulation of missing material in the Symphony no. 34, and the prior recapitulation of missing material in the Symphony no. 38.

(8) Some recapitulations begin with the second theme, the main theme following later. In these cases the transition section, altered if necessary to end on V, is placed before the second theme; in this position it acts as a retransition within the development section in addition to as a recapitulation of the transition. See Figure 2. Examples include the Piano Sonata in D Major, K. 311, and the Sonata for Violin and Piano in D Major, K. 306.

\begin{tabular}{lll} 
& \multicolumn{1}{c}{ Development } & Recapitulation \\
Model: & $---->$ retransition & MT TR ST CS \\
Variation: & $--->>$ transition & ST CS MT
\end{tabular}

Figure 2. : A model and a variation of developmentrecapitulation procedures

(9) A few works have other types of significant rearrangements of the recapitulation compared to the exposition. Two examples involving the transition may be cited: in the Flute Quartet K. 285, the main theme is shortened, the transition and subordinate theme are combined to form one small section, and the closing section is lengthened to include some 
of the missing subordinate theme. In the Piano Sonata, K. 576, the exposition has the unusual form MT-TR1-TR2-ST. In the recapitulation the main theme and the first transition are combined into one small section that also has the features of a secondary development. The second theme follows, with the second transition concluding the recapitulation. However, because the second transition is now in the tonic, because of its nature, because of its new ending, and because of its new position, it now has a new function, that of subordinate theme codetta and closing section. In short, the recapitulation here normalizes the form of an unusual exposition.

In conclusion, the main types of sonata-form transition procedures used by Mozart have been described and illustrated with several musical examples, despite the fact that there are many sub-types which make it impossible to satisfactorily explain all transitions. An indication of this large number of transition types has been given by reference to works that illustrate some of these sub-types. The analytical method employed allows one to see the form-generating elements that contribute to the structure and function of transitions, on a variety of hierarchical levels. 


\section{Appendix}

\section{Summaries of Some Theoretical Writings on the Transition}

In addition to the discussion of Green (1979) in the text, a few examples of theoretical writing on the transition will illustrate different approaches to the consideration of this subject:

Berry (1986:156-158), in discussing the harmonic function of the transition, notes that many early examples involve unconfirmed modulation, ending on $\mathrm{V}$, and cites Mozart as a composer who often uses this type. He also notes the type involving tonicization of the dominant of the new key. Unlike many authors, Berry discusses the approach to the transition, i.e., the ways it is connected to, and differentiated from, the first theme. He also considers the different types of construction of the transition, concluding his discussion with a remark appropriate to the context of this paper: "Since the art of joining two disparate formal sections is one of the most challenging aspects of composition, the reader should if possible examine carefully transitional passages of a number of periods and composers" (p. 158). I note, however, that the transition should not categorically be seen as a mere connective.

Berry discusses in slightly more detail than in most texts the possible types of changes to the transition in the recapitulation (pp. 172-174).

David (1956) focusses on development sections in sonata forms and modulations in other forms such as the Fantasy in C Minor, K. 475. His main view of modulation in the outer sections of sonata-form movements is indicated by the following quotation:

The turn from the tonic to a closely related key within the exposition is generally carried out simply and directly. The initial abrogation of the tonic is frequently set forth with considerable display of activity, by Mozart as in the works of his forerunners. This impression of activity, however, is mostly accomplished by rhythmic means rather than modulatory thrusts.... He invariably managed to outdo the modulatory effect within the exposition by an elaborate countermodulation in the recapitulation.

[1963:64]

Davis (1966) demonstrates that "Mozart appears to distinguish various areas as clearly by harmonic-rhythmic structuring as by other compositional procedures such as melodic differentiation and changes of instrumentation or tessitura" (p. 27). With respect to transition sections, he concludes that their surface rhythm is faster and has more regular note values, that transitions have a harmonic rhythm of regular long note values, and that they often involve sequences and repetition of harmonic-rhythmic patterns (p. 29). The finding of regular harmonic rhythm conflicts with my results (see my Figure 1 and related discussion). On the other hand, his finding regarding phrase structure is directly supportive of mine (i.e., my level-2 distinction between phrases and groups): 
Since $\mathrm{T}$ [transition] sections typically avoid or minimize phrase articulations, we find areas of patterned harmonic rhythm that may occupy merely the dimensions of a phrase or that may underlie a full theme or even a group of themes. The regularity of structure minimizes thematic factors and draws the attention of the ear instead to the changing harmonic situation.

Heavy terminal punctuation often provides an additional distinguishing characteristic.

Finally, he concludes that "When recapitulatory $T$ sections differ markedly from those of expositions, they tend toward increased regularity" (p. 39).

Fairleigh (1986) concentrates on the lowest level of structure - motives - and on how traditional kinds of motivic associations contribute to different types of relationships between the transition and other areas of the movement. He summarizes the purpose of the transition as ranging "from simple fulfillment of a modulatory requirement to substantial expansion of the tonal or thematic framework" (p. 15). He notes different types of harmonic structures within transitions and how these relate to thematic/motivic structures. He presents a number of diagrams to explain common patterns of exposition and recapitulation structure from the viewpoint of the transition. His discussion of recapitulation forms of transitions is useful; for example, he identifies one common pattern as comprising "three successive stages: one of untransposed or transposed recall; one of melodic, harmonic, and/or rhythmic alteration; and one of transposed recall" (p. 20).

He summarizes Mozart's transitional and retransitional sections as having generally three conditions: (1) They "create tonal tension, which resolves at least temporarily with the arrival of the next structural element;" (2) they "usually relate to at least one other position of the design;" and (3) they "are continuously composed, ranging from insignificant figuration to substantive enlargement by sequence and/or imitation. Phrase and period constructions are extremely uncommon, since they tend to produce structural autonomy - a quality ... which is detrimental to the function of transition or retransition" (p. 26).

Grave (1980) analyses a number of transitions, concluding that "the interaction of harmony and phrase rhythm stands out as a factor of organization, and the ingredients involved may be related to late eighteenth-century pedagogical writings where aspects of mobility in harmony and phrasing are codified and prescribed as stylistic norms" (p. 100). He considers the writings of Kirnberger, Vogler, and Koch in this regard.

Kohs (1976) defines the transition as "a modulating connective passage of one or more parts which is designed to prepare the listener for the new key and, probably, for new thematic material" (p. 264). This standard definition is weak in that (1) it assumes a "connective" function, when many transitions, including some of Mozart's, are more than mere connectives, and (2) it focusses only on the harmonic aspect. Kohs elaborates:

It may begin with material derived from the principal theme and end with material anticipating the second theme. There may be a thematic group, or there may be neutral material such as scales and arpeggios. The texture generally is different from that of the surrounding principal and secondary sections. In most cases, the transition closes on the dominant of the new key, perhaps on a half cadence; it may however dissolve without a cadence. 
The reference to "neutral material" is useful and is referred to in this paper (in the discussion of level 1). This factor, together with the reference to different texture, reveals that Kohs sees the exposition as comprised of differently constructed sections, a feature that certainly applies to Mozart. (See my discussion of levels 3 and 4).

Longyear (1971) considers most of Mozart's minor-mode sonata-form music, and classifies transition into the following categories: (1) The absence of a transition; (2) transitions based on the first theme (the most common type); (3) transitions using new material, and (4) transition themes. He considers that the "principal function of the transition in recapitulations is to reinforce the feeling of the tonic. Often this function is achieved by excursions into subdominant minor" (p. 210).

Ratner (1980) reviews eighteenth-century literature on sonata form, and classifies harmonic patterns of transitions as follows: "1. Equivocal approach to V .... Key area I ends on a half cadence; $\mathrm{V}$ is then treated as a key ... 2. Circle of fifths, involving tonicized degrees. 3. Interchange of mode. [I becomes $i=i v / V$ ] ... These basic patterns are often linked" (pp. 223-224). "Melodic options for the transition include (1) new material ...; (2) the opening theme ...; (3) contrasting brilliant-style material ...; or (4) a combination of these" (p. 224).

Ratz (1973) is primarily a study of eighteenth-century instrumental music. Ratz bases his approach to classical period music, and on Beethoven in particular, on the analytical principal, seen elsewhere, of differently-functioning sections. His two principles of formal organization are "(1) tightknit organization, which includes the main theme and to a certain extent the codettas, and (2) loose organization, which includes the subordinate theme, transition, retransitions, [and] development" ("fester Gefügtes (hierer rechnen wir von allem den Hauptgedanken, bis zu einem gewissen Grade auch die Schlusssätze) und locker Gefügtes (vor allem: Seitensatz, Uberleitung, Rückführung, Dürchführung ..." p. 21). His discussion of two types of transitions is worth quoting in full, because it is closely related to my approach:

The first type leads from the main key to the dominant of the new tonality. Frequently, a group of measures (for example, a four-measure phrase) is presented that still resides in the main key, so that we might imagine that this phrase is an appendix to the main theme. The four-measures are repeated during which the modulation is carried out. Then there generally comes a statement and strengthening of the dominant of the new key. We can recognize the loose organization in two characteristics: (1) the turning away from the main key, and (2) the standing on the dominant of the new key, which finds resolution only in what follows... The second type of transition appears where the modulation is already executed with the beginning of a repetition or Fortspinnung of the main theme. Then, a section, which usually is on the dominant of the new key, prepares the entrance of the subordinate theme. Here, too, the "standing on the dominant" is typical of loose organization. (Beim ersten Typ, der harmonisch von der Haupttonart zur Dominante der Zieltonart führt, wird häufig eine Gruppe, z.B. ein Viertakter aufgestellt, der noch in der Haupttonart steht, so dass wir im Zwiefel sein könnten, ob es sich nicht etwa um einen Zusatz zum Hauptthema handelt; dieser Viertakter gelangt zur Wiederholung, wobei zugleich 
die Modulation vollzogen wird; darauf folgt in der Regel noch eine Ausführung und Bekräftigung der Dominante der Zieltonart. Den lockeren Zustand sehen wir in zwei Faktoren gegeben: 1. im Sich-Wegwenden von der Ausgangstonart, 2. Im Stehenbleiben auf der Dominante der Zieltonart, das erst im Folgenden Erfüllung findet... Der zweite Typ tritt dort auf, wo im Rahmen einer angegangenen Wiederholung oder Fortspinnung des Hauptthemas die Modulation bereits vollzogen ist und nun ein Teil gewissermassen vermittelnd, meist auf der Dominante der Seitensatztonart stehend, den Eintritt des Seitensatzes vorbereitet. Auch hier haben wir, ... in diesem "Stehend auf der Dominante" einen typisch "lockeren" Zustand.

[PP. 32-33; translation by William E. Caplin]

Rosen (1971) evaluates different theories of sonata form as they apply to Haydn, Mozart, and Beethoven. In discussing the harmonic function of the transition, he writes:

The movement to the dominant was part of musical grammar, not an element of form. Almost all music in the eighteenth century went to the dominant: before $\mathbf{1 7 5 0}$ it was not something to be emphasized; afterward, it was something that the composer could take advantage of. This means that every eighteenthcentury listener expected the movement to the dominant in the sense that he would have been puzzled if he did not get it; it was a necessary condition of intelligibility.

He later discusses various means of transition (pp. 68-71); his remarks concerning the differences between the Baroque and Classical styles are especially revealing.

Rosen (1980) includes an entire chapter concerned mainly with the harmonic structure of expositions, a structure centered in the transition (chapter 9, "Exposition"). Some of the modulatory patterns and procedures he enumerates are found in works of Mozart, and most apply to music of the Classical period. I will briefly mention the patterns applicable to Mozart, retaining Rosen's numbering:

1. The transition ends on $\mathrm{V} / \mathrm{V}$, which is tonicized. Rosen uses $\mathrm{K} .333$, my example 1 , to illustrate this.

2. The transition begins with a sudden shift to a chromatic harmony, such as $\mathrm{V} / \mathrm{vi}$, and a sequence may follow to end the transition on $\mathrm{V}$.

3. While going to III in the transition is possible in the minor mode, merely going to $\mathrm{V}$ in major will not work; the transition must go to $\mathrm{V} / \mathrm{V}$ "at least if the music has any ambition" (p. 224). (This is not true of some of Mozart's transitions, as I note in my text above.)

4. "Changes of texture and rhythm occur at the point of departure from the tonic, at the arrival at the dominant, and at the confirming cadence... The first section [comprising the first theme and transition] always has an increasingly animated texture; this is as essential to the style as the modulation itself, and, indeed, helps to give the modulation its dramatic meaning" (p. 226). 
5. Alternatively, (to type 4), the second section of binary-type expositions may have the modulation; e.g., Mozart's String Quintet in G Minor, K. 516. (I note, however, that this is unusual in Mozart.)

6. Sections of the exposition are articulated partly by "alternation of regular (periodic) and irregular phrasing or changes of period" (p. 227). (Rosen gives two examples of a particular thematic structure, one the first half of the first theme from Mozart's Symphony in E-flat Major, no. 39, first movement, both of which are sentences in my terminology. See the discussion of sentence on p. 6 of my text.)

7. This division is a discussion of themes and their function in the exposition. He notes that transitions may be based on the first theme, used to articulate the movement to the dominant.

8. The dominant key is a dissonant tonality in the exposition and thus requires drastic modulatory measures in the transition, more than just a hint at $V / V$. He contrasts Mozart's and Haydn's procedures in achieving this dissonance.

9. "A move away from the tonic may be felt as imperative if the initial cadence of the statement on the tonic has been too emphatic, too final. It is very difficult to do this well; Mozart was a master of it, and [the first movement of] the Piano Sonata in F Major, K. 332, of 1778 is a beautiful example" (p. 233). This explains why this transition begins with an immediate shift to a new key (vi).

Schoenberg (1980) is closely related to Ratz (1973) in analytical method and in dealing with eighteenth-century music. An especially useful feature of Schoenberg's text is the use of many musical examples to illustrate his points. On transitions, he writes (in part):

The purpose of a transition is not only to introduce a contrast; it is, itself, a contrast. It may begin, after the end of the main theme, with new thematic formulations; or the end of the main theme may be modified thematically and harmonically into a connecting segment.

The structure of a transition ordinarily includes four elements: establishment of the transitional idea (through repetition, often sequential); modulation (often in several stages); liquidation of motival characteristics; and establishmment of a suitably upbeat chord. These aspects may overlap in varying degrees.

[P. 179]

Occasionally there is no independent transition ... But a well-developed modulatory passage between the principal and subordinate themes becomes a valuable source of contrast in the recapitulation.

Three dissertations which I have not seen but which may be useful are Montgomery (1976), Schellhous (1978), and Tangeman (1948). 


\section{REFERENCES}

BATT, $\mathbf{R}$.

1988: "A Study of Closure in Sonata-Form First Movements in Selected Works of W.A. Mozart," Ph.D. diss., Univ. of British Columbia.

BERRY, W.

1986: Form in Music. 2nd ed. Englewood Cliffs, NJ: Prentice-Hall.

CAPLIN, W.E.

1987: “The 'Expanded Cadential Progression': A Category for the Analysis of Classical Form," Journal of Musicological Research, VII, 215-257.

DAVID, H.T.

1956: "Mozartean Modulations," Musical Quarterly, XXXXII, 193-212. Reprinted in The Creative World of Mozart, ed. P.H. Lang, New York: Norton, 1963, pp. 56-75.

DAVIS, $\mathrm{S}$.

1966: "Harmonic Rhythm in Mozart's Sonata Form," Music Review, XXVII, 25-43.

FAIRLEIGH, J.

1986: "Transition and Retransition in Mozart's Sonata-Type Movements," College Music Symposium, XXVI, 14-26.

GRAVE, F.

1980: “'Rhythmic Harmony' in Mozart," Music Review, XLI, 87-102.

GREEN, D.

1979: Form in Tonal Music: An Introduction to Analysis. 2nd ed. New York: Holt, Rinehart and Winston.

KOHS, E.

1976: Musical Form: Studies in Analysis and Synthesis. Boston: Houghton Mifflin Co.

LONGYEAR, R.M.

1971: "The Minor Mode in Eighteenth-Century Sonata Form," Journal of Music Theory, XV, 182-229.

MONTGOMERY, M.F.

1976: "A Critical Analysis of the Modulations of W.A. Mozart in Selected Late Instrumental Works," Ph.D. diss., New York University.

NEWMAN, W.S.

1983: The Sonata in the Classic Era. 3rd ed. New York: Norton. 


\section{RATNER, L.}

1980: Classic Music: Expression, Form, and Style. New York: Schirmer.

\section{RATZ, E.}

1973: Einführung in die Musikalische Formenlehre. Wien: Universal Edition.

ROSEN, C.

1971: The Classical Style: Haydn, Mozart, Beethoven. New York: The Viking Press.

1980: Sonata Forms. New York: Norton.

SCHELLHOUS, R.A.

1978: "Key and Modulation in Mozart's Instructions in Figured Bass for Thomas Attwood," Ph.D. diss., Univ. of California, Santa Barbara.

SCHENKER, H.

1979: Free Composition (Der freie Satz). 2 vols. Trans. and ed. Ernst Oster. New York: Longman.

SCHOENBERG, A.

1967: Fundamentals of Musical Composition. Ed. G. Strang and L. Stein. New York: St. Martin's Press.

TANGEMAN, R.S.

1948: "The Transition Passage in Sonata Form Movements of the Viennese Classical Period," Ph.D. diss., Harvard Univ. 
Example 1 : Piano Sonata in B-flat Major, K. 333, mm. 1-63.
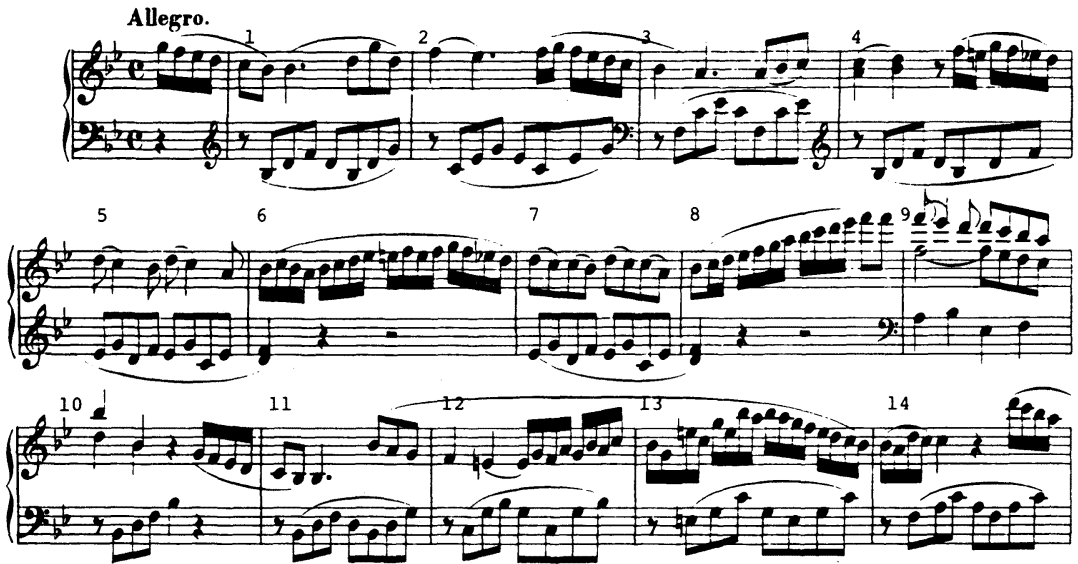

$15 \quad 16 \quad 17 \quad 18$

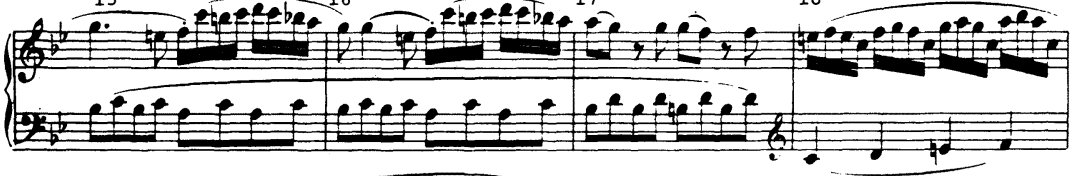

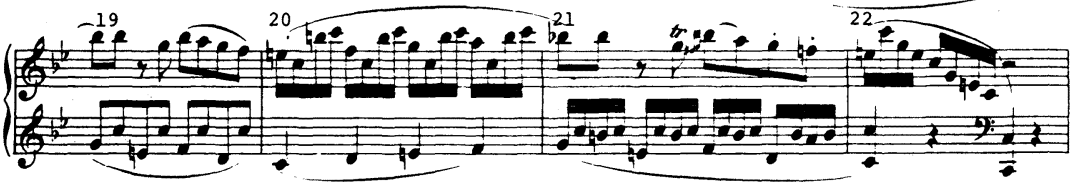

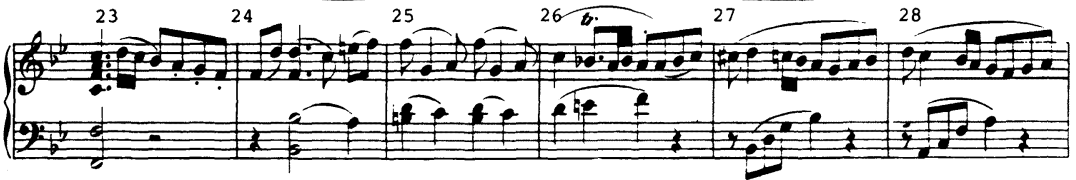

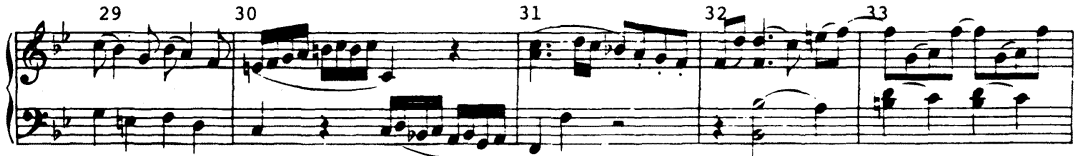


Example 1 : cont.
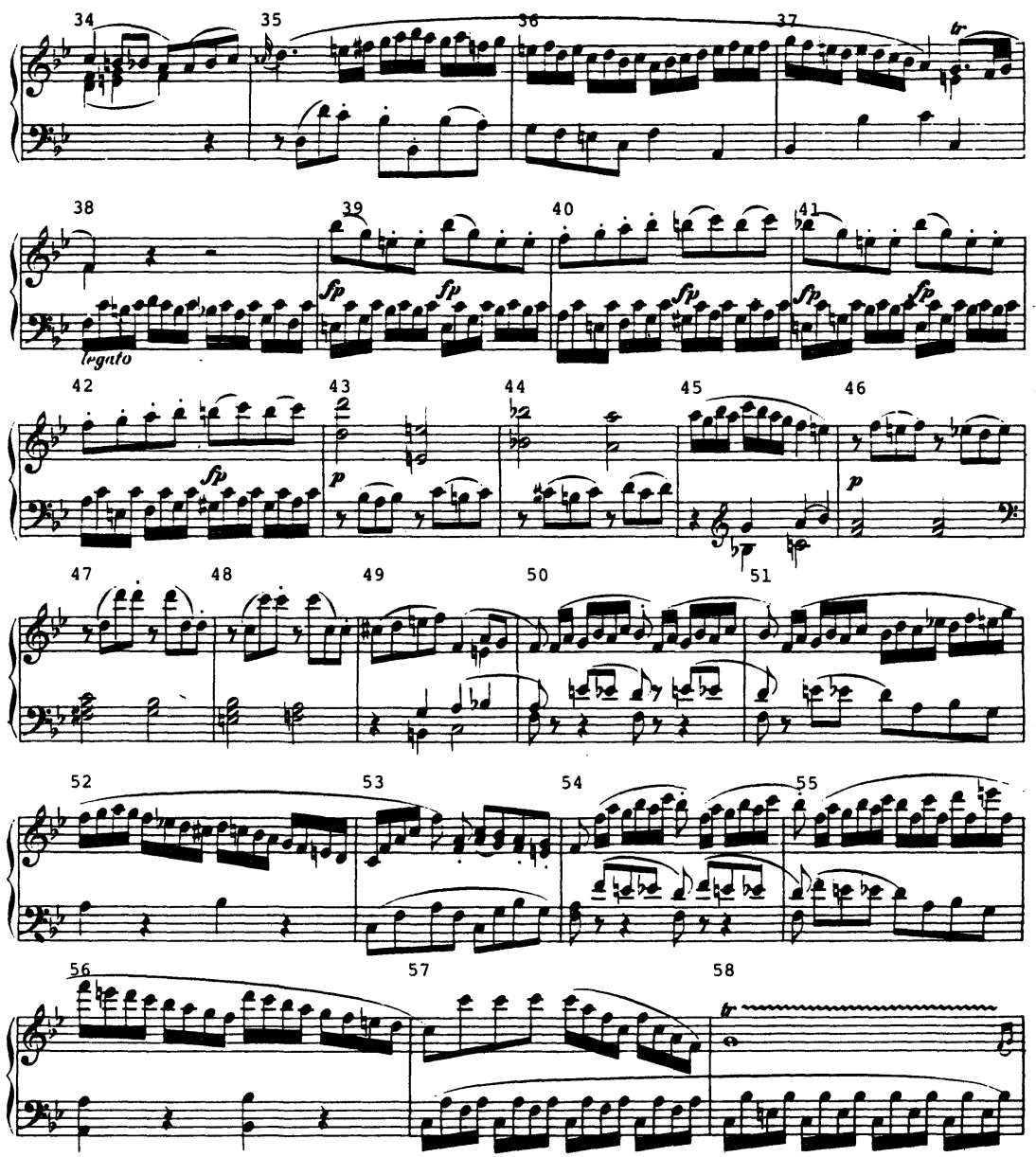

59

61

62

63

(12 + 
Example 2 : Symphony in E-flat Major, No. 39, mm. 42-105.
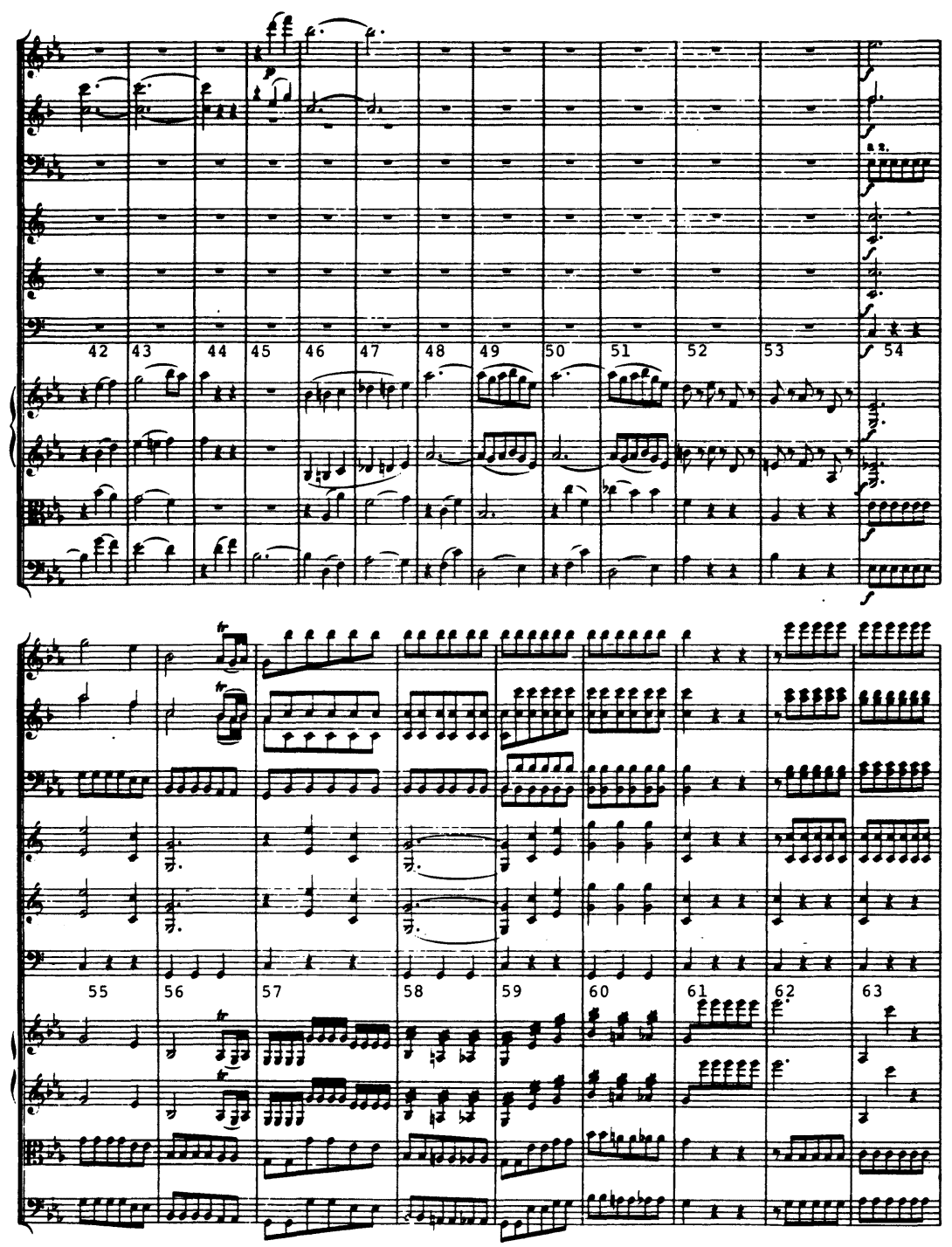
Example 2 : cont.
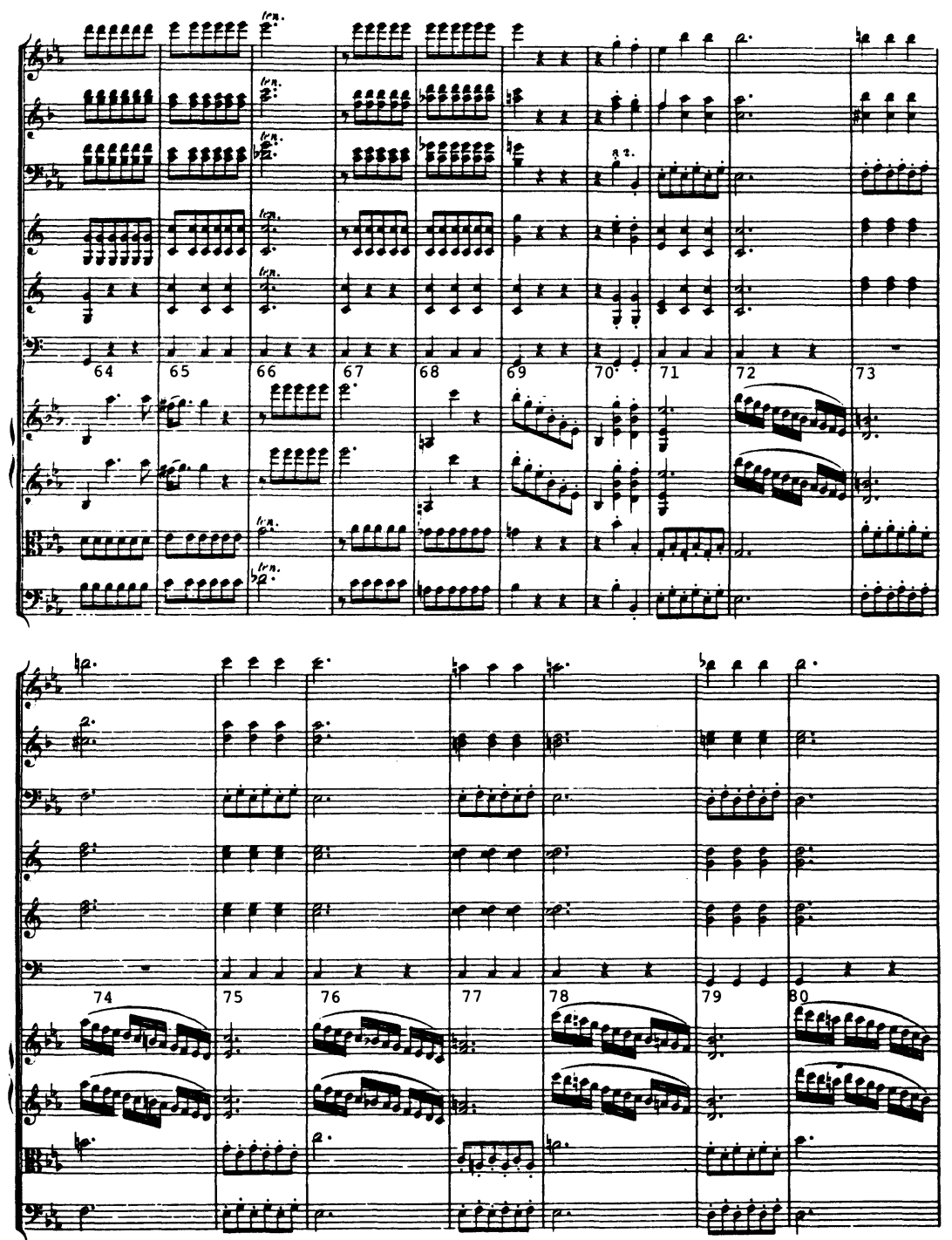
Example 2 : cont.
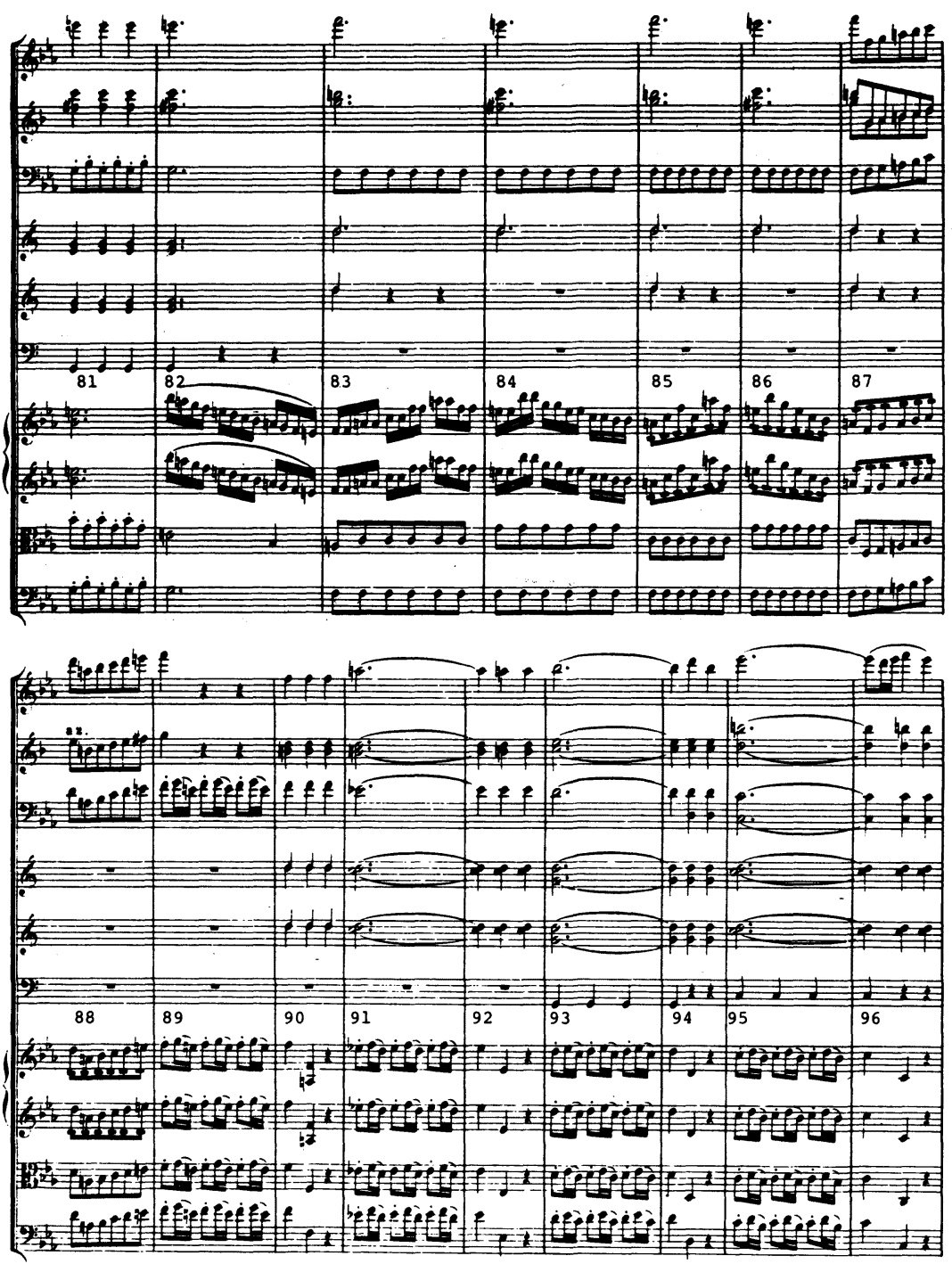
Example 2 : cont.

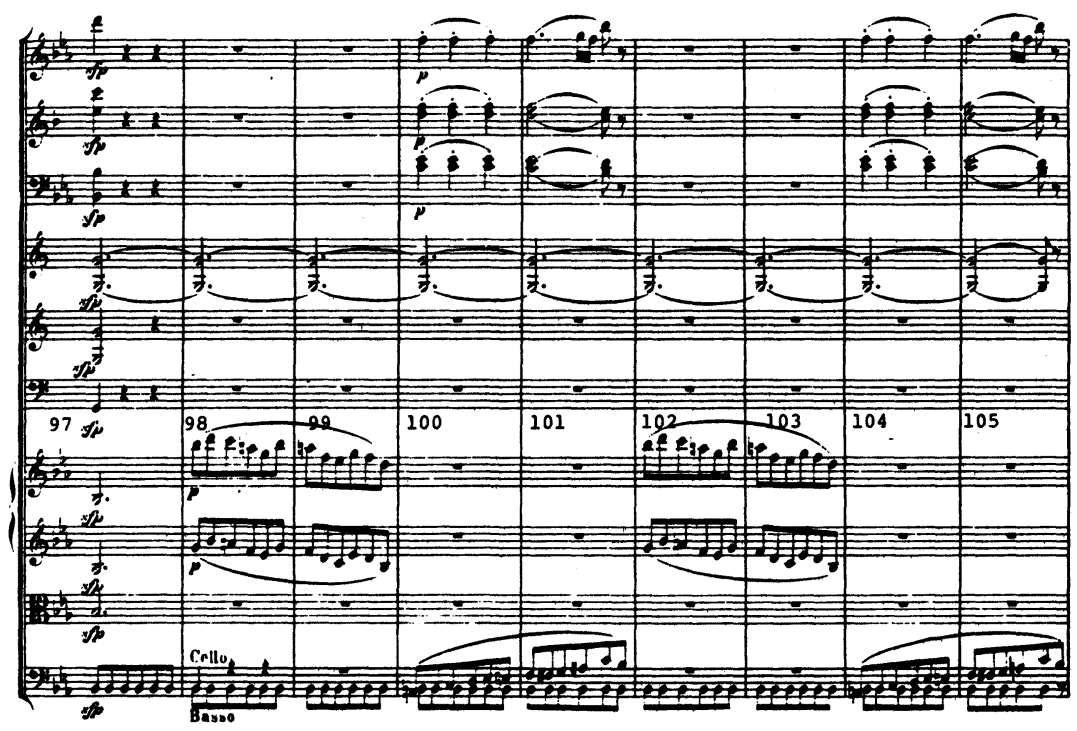


Example 3 : Serenade in C Minor, K. 388, mm. 1-43.
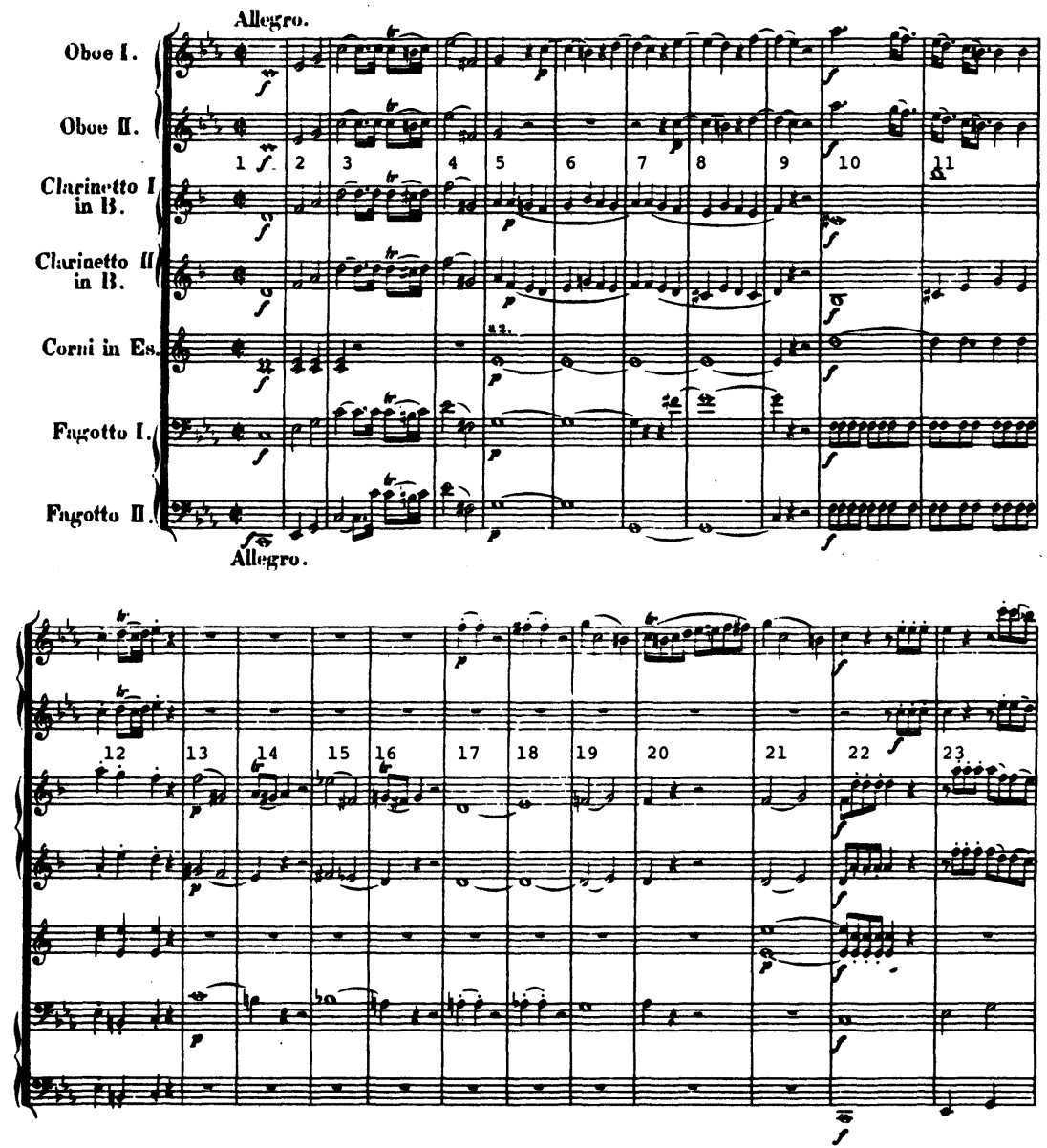
Example 3 : cont.
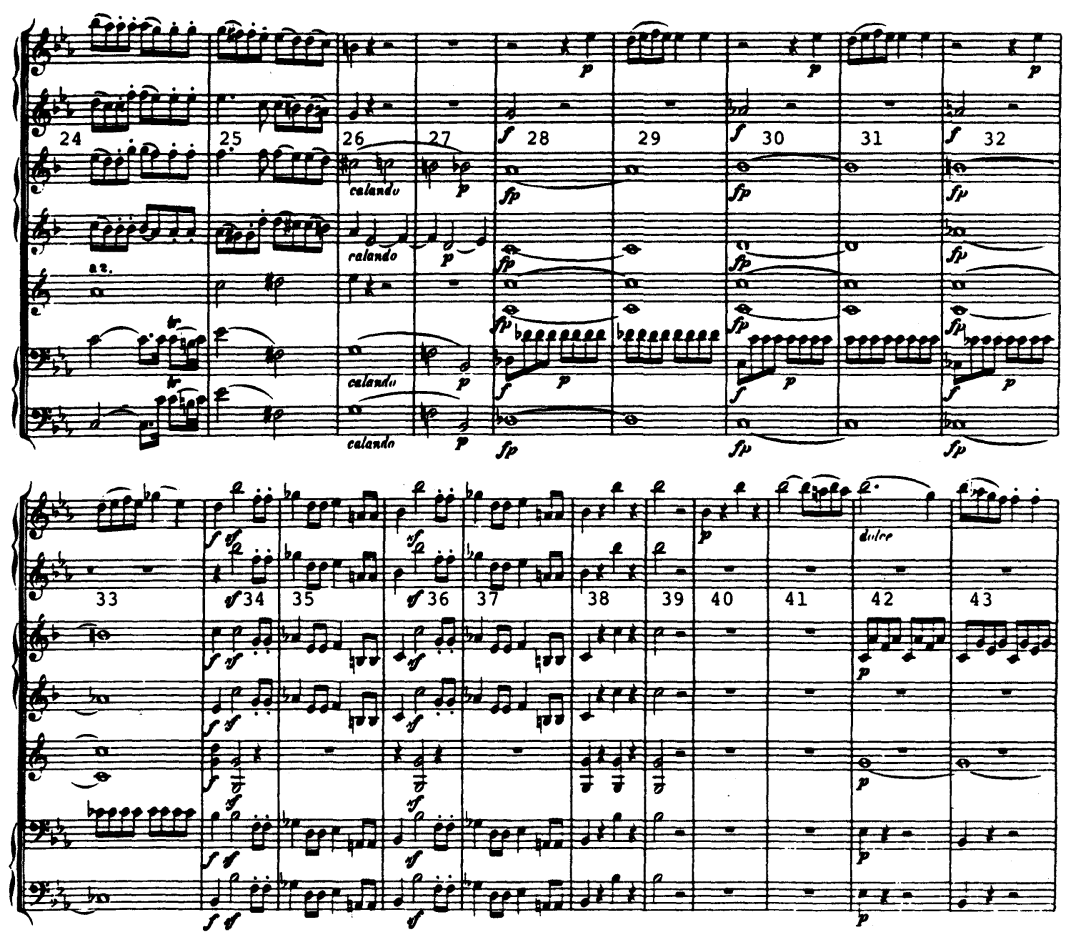
Example 4 : Sonata for Violin and Piano in B-flat Major, K. 454, mm. 14-32 and mm. 96-114.
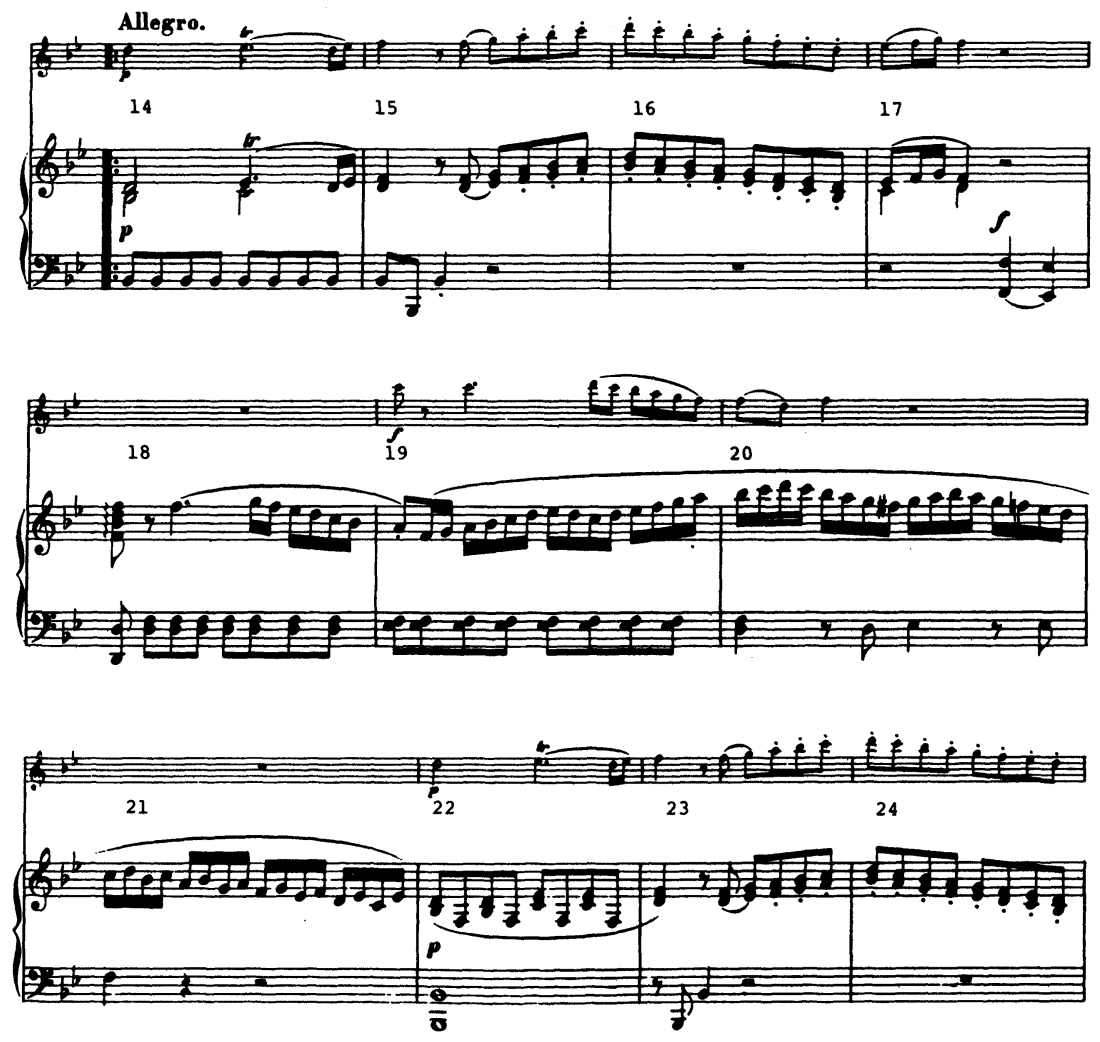
Example 4 : cont.
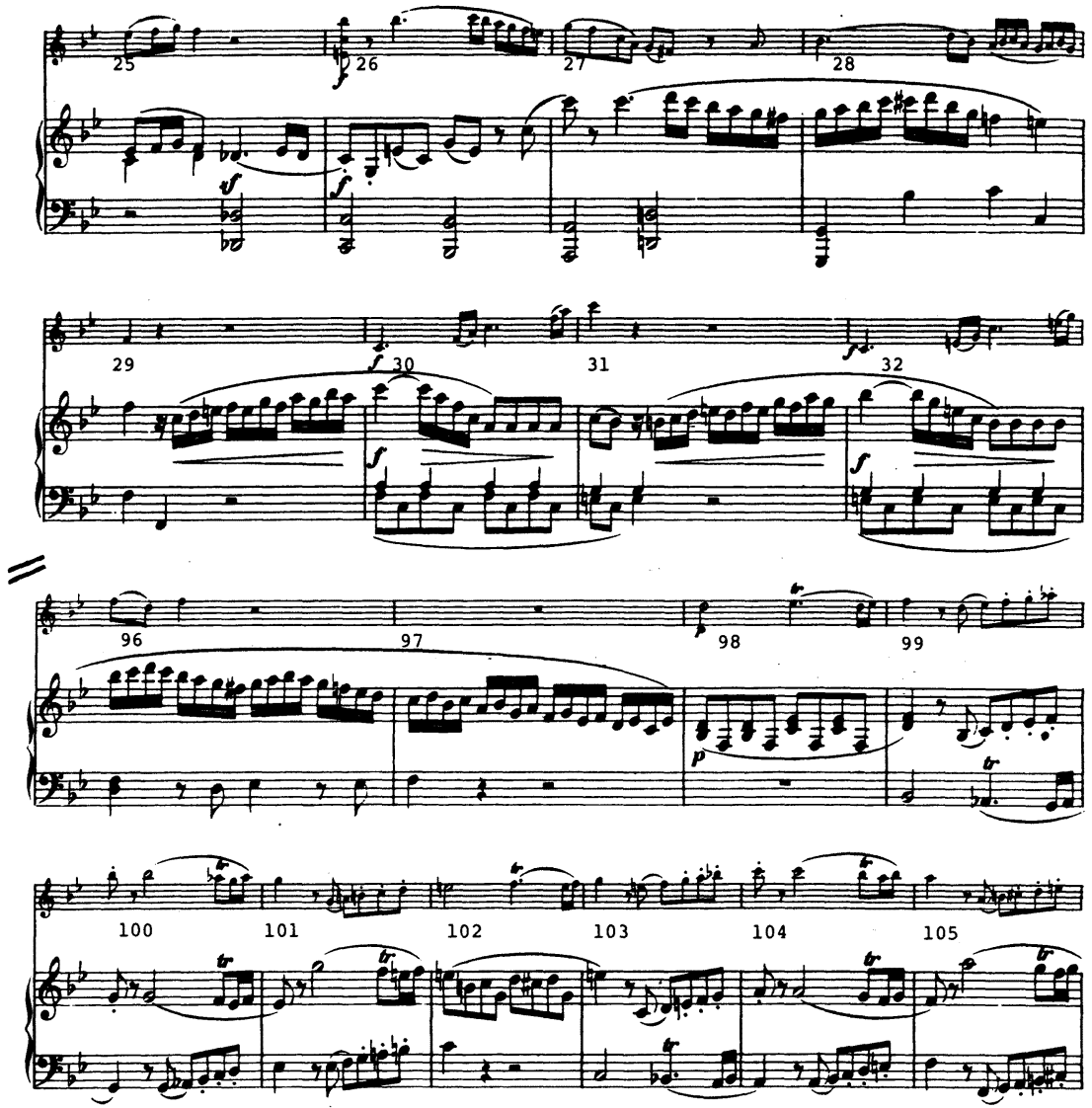
Example 4 : cont.
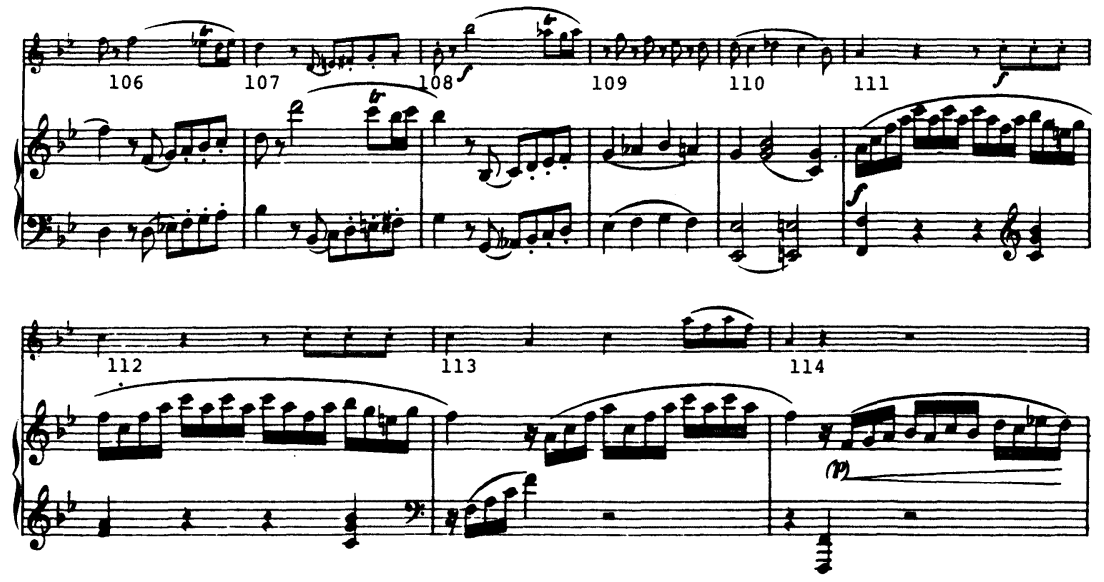